\title{
Incidence of Hypotension between Intrathecal Hyperbaric Bupivacaine with and without Fentanyl in Geriatric Patients Undergoing Urological Surgeries
}

\author{
Thavat Chanchayanon, M.D. ${ }^{1}$, Mareeya Chearong, M.D. ${ }^{2}$, Piyaporn Vasinanukorn, M.D. ${ }^{1}$, \\ Natsana Withayanuphakorn, B.S. ${ }^{1}$, Tidarat Sangkaew, B.S. ${ }^{1}$
}

${ }^{1}$ Department of Anesthesiology, Faculty of Medicine, Prince of Songkla University, Hat Yai, Songkhla 90110, Thailand.

${ }^{2}$ Pattani Hospital, Mueang, Pattani 94000, Thailand.

Received 18 October 2018 • Revised 11 February 2019 • Accepted 18 February 2019 • Published online 14 March 2019

\section{Abstract:}

Objective: We aimed to assess the efficacy, the incidence of hypotension and adverse consequences of using intrathecal hyperbaric bupivacaine in comparison to a combination of low dose hyperbaric bupivacaine and fentanyl, in geriatric patients undergoing urological surgeries.

Material and Methods: Our study was a prospective, triple-blinded and randomized controlled. One hundred and fortyeight geriatric participants scheduled for urological surgeries were randomly assigned into two groups: Group B ( $n=74)$ received intrathecal injection with $0.5 \%$ hyperbaric bupivacaine 1.5 milliliters $(\mathrm{ml})$ alone $(7.5$ milligrams; $\mathrm{mg}$ ), while Group $\mathrm{F}(\mathrm{n}=74)$ received $0.5 \%$ hyperbaric bupivacaine $1 \mathrm{ml}(5 \mathrm{mg})$ plus $0.5 \mathrm{ml}$ of fentanyl (25 micrograms; $\mathrm{mcg}$ ) making up to a total volume of $1.5 \mathrm{ml}$.

Results: One hundred and forty-eight patients were included however, six patients were excluded from statistical analysis, due to an inadequate level of anesthesia; hence, 142 patients were analyzed. The incidence of hypotension in group $B$ was: $9.7 \%$, and in group $F$ the percentage was $12.9 \%$, respectively ( $p$-value $=0.74$ ). There was no significant difference in regards to the highest sensory level in both groups. The anesthesia level in group B was Thoracic level 11 (T10-T12), and in group $F$ it was 11 (T10-T12) ( $p$-value=0.68), while the analgesia level in group $B$ was Thoracic level 7 (T6-T8) with group $F$ being a Thoracic level 6 (T6-T8) ( $p$-value=0.16). The occurrence of bradycardia, and respiratory depression did not differ between the 2 groups.

Contact: Assoc. Prof. Thavat Chanchayanon, M.D.

Department of Anesthesiology, Faculty of Medicine, Prince of Songkla

University, Hat Yai, Songkhla 90110, Thailand.

E-mail: cardiacpsu@gmail.com
J Health Sci Med Res 2019;37(2):93-99 doi: 10.31584/jhsmr.201944 www.jhsmr.org 
Conclusion: Intrathecal administration of $5 \mathrm{mg}$ of $0.5 \%$ hyperbaric bupivacaine, plus 25 mcg of fentanyl provided an adequate level of sensory blockade, but did not decrease the frequency of hypotension.

Keywords: geriatric, hyperbaric bupivacaine, hypotension, spinal anesthesia, urological surgeries

\section{Introduction}

We commonly use spinal anesthesia as an anesthetic modality for geriatric urological patients scheduled for surgeries ${ }^{1}$, as it is thought that spinal anesthesia is able to maintain cerebral function. ${ }^{2}$ Spinal anesthesia for urological surgeries offers rapid onset of action, relaxation of muscle as well as pain relief. ${ }^{3}$ However, intraoperative hypotension is a frequent, and somewhat serious consequence within the geriatric population. ${ }^{4,5}$

As well as this, many of them have underlying medical conditions, thus it is quite crucial to reduce the level of spinal blockade in order to avoid cardiopulmonary adverse effects. ${ }^{6}$ Utilization of low-dose bupivacaine is suggested, but it may not provide a sufficient block for surgery. ${ }^{7,8}$

Adding opioids, with local anesthetic, leads to a better quality of intraoperative analgesia. ${ }^{9}$ It was shown that a combination of intrathecal opioids, and local anesthetic provides an analgesic effect in a synergistic way. ${ }^{10,11}$

Morphine is the first opioid used intrathecally, but comes with a wide variety of clinically relevant side-effects, especially respiratory depression. This has limited its utility. ${ }^{12}$ Favorable pharmacokinetic and pharmacodynamics profiles of lipophilic opioids, for example; fentanyl, makes them better alternatives, because of a rapid uptake, faster onset and shorter duration of action. This minimizes the rostral spread of the lipophilic drugs to reach the respiratory center avoiding delayed respiratory depression. ${ }^{13}$

Adding fentanyl to low doses of local anesthetic increases the quality of the spinal blockage as well as the duration of the sensory block. ${ }^{14,15}$ Kuusniemi et al. ${ }^{16}$ demonstrated that mixing 25 micrograms (mcg) of fentanyl to $5 \mathrm{mg}$ of bupivacaine provided an effective level of an esthesia and motor block. Gupta et al., ${ }^{17}$ revealed that intrathecal administration with 7.5 milligrams $(\mathrm{mg})$ of bupivacaine contributed to $13.3 \%$ of hypotension, whereas, a decreased dose of bupivacaine to $5 \mathrm{mg}$, in combination with fentanyl 25 mcg resulted in no event of hypotension.

We intended to assess the effects of giving 7.5 $\mathrm{mg}$ of bupivacaine intrathecally in comparison to $5 \mathrm{mg}$ of bupivacaine, plus $25 \mathrm{mcg}$ of fentanyl in elderly patients undergoing urological surgeries.

\section{Material and Methods}

This trial was approved by the Ethics Committee of the Faculty of Medicine, Prince of Songkla University, Songkhla, Thailand, on the $5^{\text {th }}$ of September 2016 (EC 59-182-08-1). Its registered number is TCTR 2017012001.

\section{Participants}

We included 148 American Society of Anesthesiologists Physical Status (ASA) classes II-III participants. Their age had to be at least 65 years old. All of them were scheduled for elective urological surgeries, under spinal anesthesia, between; October 2016 and July 2017.

We excluded those with abnormalities of the spine, skin infections on the targeted area, a known allergy to amide local anesthetics, abnormal bleeding tendency, did not want to proceed with spinal anesthesia, or had recieved inadequate anesthesia. 


\section{Standard operating procedures}

All participants gave written informed consent. Before performing spinal anesthesia, crystalloid $500 \mathrm{ml}$ was given to each patient.

Patients were randomly assigned to either of the 2 groups ( $\mathrm{B}$ or $\mathrm{F}$ ) by using a randomized computergenerated sequence. The sequenced numbers were kept in a separate, opaque envelope.

Patients in group $B(n=74)$ received intrathecal administration of $7.5 \mathrm{mg}$ of $0.5 \%$ bupivacaine, while those in group $F(n=74)$ received intrathecal injection of $5 \mathrm{mg}$ of $0.5 \%$ bupivacaine, plus $25 \mathrm{mcg}$ of fentanyl.

A $1.5 \mathrm{ml}$ identical solution was prepared for all subjects. The syringes had no identity to indicate group allocation.

Spinal anesthesia was done by an attending anesthesiologist, who was blinded to the subject assignment. All spinal anesthesia was performed at L3-L4 level, using a 27G Quincke needle in either lateral decubitus or sitting position.

After the procedure, each patient was frequently measured for systolic blood pressure (SBP), diastolic blood pressure (DBP) and mean arterial blood pressure (MAP). All parameters were recorded every minute, for the first 15 minutes and then every 5 minutes until the surgery finished.

Levels of spinal block was examined by a pinprick test every 2 minutes, until the maximum and fixed level had been established. The highest levels of both anesthesia and analgesia were recorded. The levels of motor block were measured by using the Bromage score: $0=$ no motor blockage, 1=hip blocked, 2=hip and knee blocked, 3=hip, knee and foot blocked, consequently. Follow-up was carried out every 10 minutes during postanesthesia care, until the patients were discharged.

\section{Outcome of the study}

The incidence of hypotension was the primary outcome of this study.

Secondary endpoints were: levels of anesthesia, analgesia and motor blockade. Adverse events were also considered as secondary endpoints.

Hypotension was clarified as: SBP $<20.0 \%$ of preoperative value, or $\mathrm{MAP}<60 \mathrm{mmHg}$. Hypotension was managed using $6 \mathrm{mg}$ of ephedrine or $10 \mathrm{mcg}$ of norepinephrine, given intravenously.

Bradycardia was clarified as: a heart rate $<45$ beats/minute, with this being managed by intravenous administration of $0.6 \mathrm{mg}$ of atropine.

Respiratory depression was clarified as: a respiratory rate $<10$ beats/minute or oxygen saturation $<90.0 \%$, with room air. All patients were given supplemental oxygen via face mask at 6 liters/minute.

If a patient had nausea or vomiting, ondansetron $0.1 \mathrm{mg} / \mathrm{kg}$ was given intravenously.

Any patient who complained of itching was given a single dose of $10 \mathrm{mg}$ of chlorpheniramine intravenously.

\section{Sample size calculation}

Based on previous research ${ }^{17}$ a statistical power analysis was performed for sample size estimation. To detect a $13.0 \%$ difference in complication rates, with a significance level set to 0.05 and a power set to 0.8 , 70 samples per group were required. Based on a dropout rate of $10.0 \%$, total sample size of 156 was needed (78 patients per each group).

\section{Statistical analysis}

Continuous variables were shown as median and interquartile range (IQR) for non-normally distributed data, or mean and standard deviation (S.D.) for normally distributed data. 
Categorical variables were demonstrated as frequency and percentage, whilst the comparison of continuous variables were acquired by using two-way analysis of Student's t-test. Categorical variables were compared by using Fisher's exact test, with any changes in SBP, DBP, and MAP being compared by using generalized estimating equation.

A $p$-value value of less than 0.05 was regarded as statistically significant. The per-protocol analysis was applied in this study.

\section{Results}

Figure 1 revealed the details of the 148 patients included in this study. Patient characteristics are demonstrated in Table 1. There was no difference of demographic data between the 2 groups.

No difference in the incidence of hypotension (SBP, DBP and MAP) was found between the 2 groups (Table 2, Figure 2).

The incidences of unwanted consequences between the 2 groups are displayed in Table 3. No significant differences were demonstrated.

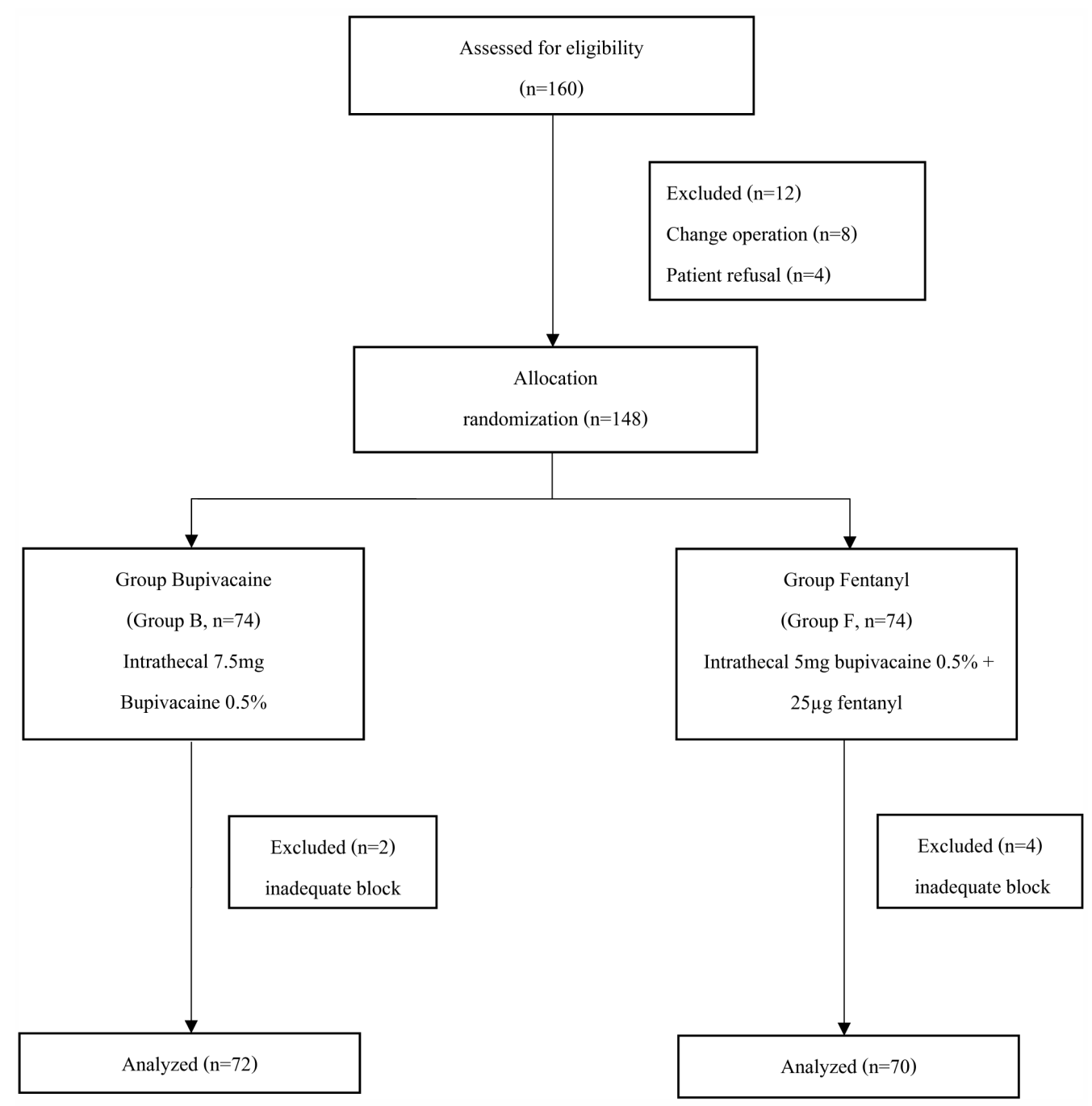

Figure 1 Consort flow diagram 
Table 1 Demographic data and anesthesia related information

\begin{tabular}{|c|c|c|c|}
\hline Parameter & $\begin{array}{l}\text { Group B } \\
(n=72)\end{array}$ & $\begin{array}{l}\text { Group F } \\
(n=70)\end{array}$ & P-value \\
\hline Age (years), median (IQR) & $71(67,79)$ & $72(67,78)$ & 0.79 \\
\hline Body mass index $\left(\mathrm{kg} / \mathrm{m}^{2}\right)$, mean (S.D.) & $24(3.8)$ & $25(4)$ & 0.11 \\
\hline \multicolumn{4}{|l|}{ ASA, number (\%) } \\
\hline II & $53(73.6)$ & $55(78.6)$ & \multirow[t]{2}{*}{0.66} \\
\hline III & $19(26.4)$ & $15(21.4)$ & \\
\hline \multicolumn{4}{|l|}{ Number of spinal attempt (\%) } \\
\hline 1 attempt & $43(59.7)$ & $43(61.4)$ & \multirow[t]{2}{*}{0.97} \\
\hline$>1$ attempt & $29(40.3)$ & $27(38.6)$ & \\
\hline \multicolumn{4}{|l|}{ Position of patients during spinal block (\%) } \\
\hline Lateral decubitus & $72(100.0)$ & $69(98.6)$ & \multirow[t]{2}{*}{0.49} \\
\hline Sitting & $0(0.0)$ & $1(1.4)$ & \\
\hline \multicolumn{4}{|l|}{ Adjustment of position of operating table (\%) } \\
\hline No adjustment & $41(56.9)$ & $44(62.9)$ & \multirow[t]{2}{*}{0.58} \\
\hline With adjustment & $31(43.1)$ & $26(37.1)$ & \\
\hline Duration (mins), median (IQR) & $40(30,55)$ & $40(30,60)$ & 0.55 \\
\hline Use of ephedrine (mg), median (IQR) & $12(8,12)$ & $6(6,11)$ & 0.45 \\
\hline Use of norepinephrine (mcg), median (IQR) & $20(15,25)$ & $10(10,10)$ & 1.00 \\
\hline Use of atropine (mg), median (IQR) & $0(0,0)$ & $0.6(0.6,0.6)$ & 1.00 \\
\hline Estimate blood loss (ml), median (IQR) & $50(20,158)$ & $50(10,155)$ & 0.41 \\
\hline
\end{tabular}

IQR=interquartile range, S.D.=standard deviation, $\mathrm{mg}=$ =milligram, $\mathrm{ml}=$ milliliter, $\mathrm{ASA}=$ American Society of Anesthesiologist classification, $\mathrm{mcg}=$ microgram

Table 2 Incidence of hypotension, maximum levels of anesthesia and analgesia and level of motor blockade

\begin{tabular}{|c|c|c|c|}
\hline Parameter & $\begin{array}{l}\text { Group B } \\
(n=72)\end{array}$ & $\begin{array}{l}\text { Group F } \\
(n=70)\end{array}$ & P-value \\
\hline Incidence, n (\%) & $7(9.7)$ & $9(12.9)$ & 0.74 \\
\hline Maximum level of anesthesia, median (IQR) & $11(10,12)$ & $11(10,12)$ & 0.68 \\
\hline Maximum level of analgesia, median (IQR) & $7(6,8)$ & $6(6,8)$ & 0.16 \\
\hline \multicolumn{4}{|l|}{ Motor block by Bromage score, $\mathrm{n}(\%)$} \\
\hline $0=$ no motor block & $5(6.9)$ & $5(7.1)$ & 0.98 \\
\hline 1=hip blocked & $3(4.2)$ & $4(5.7)$ & \\
\hline 2=hip and knee blocked & $5(6.9)$ & $5(7.1)$ & \\
\hline $3=$ hip, knee and ankle blocked & 59 (81.9) & $56(80.0)$ & \\
\hline
\end{tabular}

$I Q R=$ interquartile range 


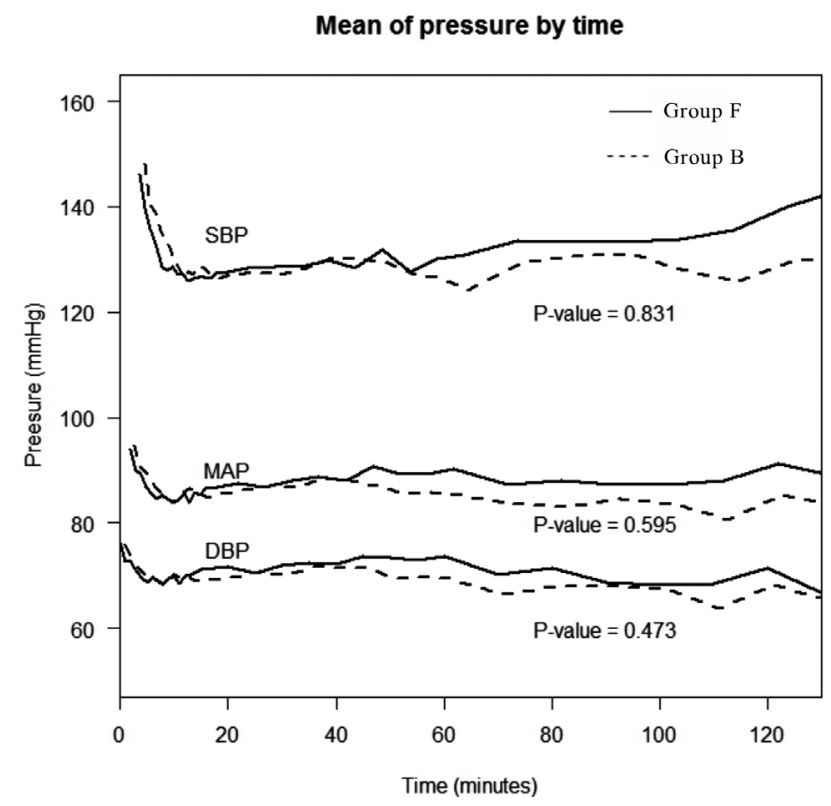

Figure 2 Comparison of changes in systolic blood pressure, diastolic blood pressure and mean arterial blood pressure between the 2 groups.

Table 3 Adverse events, data were shown in number

\begin{tabular}{llll}
\hline Parameter & $\begin{array}{l}\text { Group B } \\
(\mathbf{n}=72) \\
\text { Number }(\%)\end{array}$ & $\begin{array}{l}\text { Group F } \\
(\mathbf{n}=70)\end{array}$ & Pumber $(\%)$ \\
\hline Bradycardia & $0(0.0)$ & $2(2.9)$ & 0.24 \\
Respiratory depression & $2(2.8)$ & $1(1.4)$ & 1.00 \\
Nausea & $2(2.8)$ & $6(8.6)$ & 0.16 \\
Vomiting & $2(2.8)$ & $4(5.7)$ & 0.44 \\
Itching & $1(1.4)$ & $2(2.9)$ & 0.62 \\
Shivering & $4(5.6)$ & $3(4.3)$ & 1.00 \\
\hline
\end{tabular}

\section{Discussion}

The 2 groups showed the same efficacy of spinal block by measuring and comparing the levels of anesthesia, analgesia and motor blockade. Our results are compatible with those from the study done by Gupta et al. $^{17}$
The Gupta et al. ${ }^{17}$ study found $13.0 \%$ of hypotension in group B. However, there was no hypotension found in Group F. This was different from our study, as hypotension was found in $12.9 \%$ of patients in group $F$. The dose of fentanyl $25 \mathrm{mcg}$, administered intrathecally, may be too high for Thai people. Additionally, the average age of patients in our study was 71 years old. Elderly patients may be more susceptible to sustained hypotension in comparison to younger patients, in so saying, Gupta et al.'s ${ }^{17}$ patients' age were 62.9 years of age on average. Gupta et al. ${ }^{17}$ found that group B had 3.3\% of bradycardia. Group $\mathrm{F}$ had $3.3 \%$ of pruritus. No respiratory depression was found in both groups. Again, this result was different from our study, which found more side effects in group $F$ than group $B$, however this was not statistically significance. Bradycardia was not evident in group $B$, but $2.9 \%$ of patients in group $\mathrm{F}$ had this finding. Group $\mathrm{F}$ had half the incidence of respiratory depression in comparison to group $\mathrm{B}$.

This study demonstrated that spinal anesthesia, with a low dose of $0.5 \%$ bupivacaine $(1 \mathrm{ml})$ in combination with $25 \mathrm{mcg}$ of fentanyl provided adequate anesthesia, which was similar to using $0.5 \%$ bupivacaine $(1.5 \mathrm{ml})$ alone in geriatric patients undergoing urological surgeries.

There were no significant differences in the occurrence of: bradycardia, respiratory depression, shivering, vomiting, nausea or itching between the 2 groups.

\section{Strengths and limitations}

Our study was triple-blinded, with no bias of assessment.

We suggest to compare different doses of $0.5 \%$ hyperbaric bupivacaine $(5,7.5$ and $10 \mathrm{mg})$, with and without fentanyl. Furthermore, we suggest further studies aiming to reduce the dose of intrathecal fentanyl (for example: 20 
mcg), as this may be beneficial in terms of adverse event reduction.

One weakness of our study was the uncertainty and variety of anesthesiologists performing spinal anesthesia, which might have had an effect on the level of anesthesia and incidence of hypotension.

\section{Conclusion}

Intrathecal bupivacaine $5 \mathrm{mg}$ in combination with fentanyl 25 mcg gives adequate anesthesia for geriatrics patients undergoing urological surgeries, when compared to a usual dose of bupivacaine $(7.5 \mathrm{mg})$. The overall incidence of adverse events did not differ in both groups.

\section{Conflict of interest}

No potential conflict of interest relevant to this article was reported.

\section{References}

1. Kararmaz A, Kaya S, Turhanoglu S, Ozyilmaz MA. Low dose bupivacaine-fentanyl spinal anesthesia for transurethral prostatectomy. Anaesthesia 2003;58:526-30.

2. Hole A, Terjesen T, Breivig H. Epidural versus general anesthesia for total hip arthroplasty in elderly patients. Acta Anaesthesiol Scand 1980;24:279-87.

3. Rubin AP. Spinal anesthesia. In: Wildsmith JA, editor. Principles and practice of regional anesthesia. London: Churhill Livingstone; 1998;p.70-80.

4. Vaghadia $H$, McLeod DH, Mitchell GW, Merrick PM, Chilvers CR. Small-dose hypobaric lidocaine-fentanyl spinal anesthesia for short duration outpatient laparoscopy. A randomized comparison with conventional dose hyperbaric lidocaine. Anesth Analg 1997;84:59-64.

5. Critchley LA. Hypotension, subarachnoid block and the elderly patient. Anaesthesia 1996;51:1139-43.

6. Rooke GA, Freund PR, Jacobson AF. Hemodynamic response and change in organ blood volume during spinal anesthesia in elderly men with cardiac disease. Anesth Analg 1997;85: 99-105.

7. Singh I, Gupta M, Mahawar B, Gupta A. Comparison of effect of intrathecal sufentanil-bupivacaine and fentanyl-bupivacaine combination on postoperative analgesia. Indian $\mathrm{J}$ Anaesth 2008;52:301-4.

8. Gautier PE, De Kock M, Van Steenberge A, Poth N, LahayeGoffart B, Fanard L, et al. Intrathecal ropivacaine for ambulatory surgery. Anesthesiology 1999;91:1239-45.

9. Hunt CO, Naulty JS, Bader AM, Hauch MA, Vartikar JV, Datta $\mathrm{S}$, et al. Perioperative analgesia with subarachnoid fentanylbupivacaine for cesarean delivery. Anesthesiology 1989;71: 535-40.

10. Maves TJ, Gebhart GF. Antinociceptive synergy between intrathecal morphine and lidocaine during visceral and somatic nociception in the rat. Anesthesiology 1992;76:91-9.

11. Wang C, Chakrabarti MK, Whitwam JG. Specific enhancement by fentanyl of the effects of intrathecal bupivacaine on nociceptive afferent but not on sympathetic efferent pathways in dogs. Anesthesiology 1993;79:766-73.

12. Bromage PR, Camporesi EM, Durant PA, Nielsen $\mathrm{CH}$. Rostral spread of epidural morphine. Anesthesiology 1982;56:431-6.

13. Singh C, Trikha A, Saxena A. Spinal Anaesthesia with bupivacaine and fentanyl. J Anaesthesiol Clin Pharmacol 1999;15: 291-4.

14. Chen TY, Tseng CC, Wang LK, Tsai TY, Chen BS, Chang CL. The clinical use of small-dose tetracaine spinal anesthesia for transurethral prostatectomy. Anesth Analg 2001;92:1020-3.

15. Liu S, Chiu AA, Carpenter RL, Mulroy MF, Allen HW, Neal JM, et al. Fentanyl prolongs lidocaine spinal anesthesia without prolonging recovery. Anesth Analg 1995;80:730-4.

16. Kuusniemi KS, Pihlajamakin KK, Pitkanen MT, Helenius HY, Kirvela OA. The use of bupivacaine and fentanyl for spinal anesthesia for urologic surgery. Anesth Analg 2000;91: 1452-6.

17. Gupta S, Sampley S, Kathuria S, Katyal S. Intrathecal sufentanil or fentanyl as adjuvants to low dose bupivacaine in endoscopic urological procedures. J Anaesthesiol Clin Pharmacol 2013;29:509-15. 